\title{
Food consumption of Sri Lankan adults: an appraisal of serving characteristics
}

\author{
Ranil Jayawardena ${ }^{1,2, *}$, Nuala M Byrne ${ }^{1}$, Mario J Soares ${ }^{3}$, Prasad Katulanda ${ }^{2}$ and \\ Andrew P Hills ${ }^{4}$ \\ ${ }^{1}$ Institute of Health and Biomedical Innovation, Faculty of Health, Queensland University of Technology, \\ 60 Musk Avenue, Kelvin Grove, QLD 4059, Australia: ${ }^{2}$ Diabetes Research Unit, Department of Clinical \\ Medicine, Faculty of Medicine, University of Colombo, Colombo, Sri Lanka: ${ }^{3}$ Curtin Health Innovation \\ Research Institute, School of Public Health, Faculty of Health Sciences, Curtin University, Perth, WA, Australia: \\ ${ }^{4}$ Mater Mother's Hospital, Mater Medical Research Institute and Griffith Health Institute, Griffith University, \\ Brisbane, QLD, Australia
}

Submitted 29 January 2012: Final revision received 19 March 2012: Accepted 30 April 2012: First published online 12 July 2012

\begin{abstract}
Objective: The main aim of the present study was to identify food consumption in Sri Lankan adults based on serving characteristics.

Design: Cross-sectional study. Fruits, vegetables, starch, meat, pulses, dairy products and added sugars in the diet were assessed with portion sizes estimated using standard methods.

Setting: Twelve randomly selected clusters from the Sri Lanka Diabetes and Cardiovascular Study.

Subjects: Six hundred non-institutionalized adults.

Results: The daily intake of fruit $(0 \cdot 43)$, vegetable $(1 \cdot 73)$ and dairy $(0 \cdot 39)$ portions were well below national recommendations. Only $3.5 \%$ of adults consumed the recommended 5 portions of fruits and vegetables/d; over a third of the population consumed no dairy products and fewer than $1 \%$ of adults consumed 2 portions/d. In contrast, Sri Lankan adults consumed over 14 portions of starch and 3.5 portions of added sugars daily. Almost $70 \%$ of those studied exceeded the upper limit of the recommendations for starch intake. The total daily number of meat and pulse portions was $2 \cdot 78$.

Conclusions: Dietary guidelines emphasize the importance of a balanced and varied diet; however, a substantial proportion of the Sri Lankan population studied failed to achieve such a recommendation. Nutrition-related diseases in the country may be closely correlated with unhealthy eating habits.
\end{abstract}

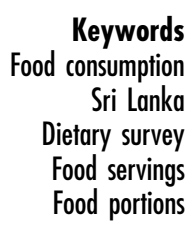

Sri Lanka is a developing country in South Asia undergoing rapid socio-economic transition in which both over- and undernutrition are serious health concerns. In 2005, the prevalence of hypertension, diabetes and dysglycaemia in Sri Lanka was nearly 20\%, 11\% and 20\%, respectively ${ }^{(1,2)}$. Although Sri Lanka is a developing country, it has recorded 524 deaths per 100000 for mortality from cardiovascular and cerebrovascular disease, a figure which is considerably higher than the rate in many affluent countries such as the UK (427), the USA (397), Australia (308) and France $(205)^{(3)}$. Despite Sri Lanka having a very high prevalence of non-communicable diseases (NCD) and associated mortality, little is known about the causative factors. It is widely believed that the NCD epidemic in the country is partially associated with unhealthy dietary habits ${ }^{(3)}$.

Food intake patterns play an essential role in the maintenance of health and well-being at both individual and population levels. Food products supply energy and essential macro- and micronutrients; however, over- or undernutrition has the potential to cause serious health consequences $^{(4)}$. A national-level dietary survey has several important functions and provides valuable information. Survey data are also helpful to monitor nutritional status, observe dietary practices and study the relationships between diet and disease. The main objective of the present study was to identify food consumption according to servings in Sri Lankan adults. In addition, we aimed to derive serving sizes and food exchange information not presently available for some food groups in Sri Lanka.

\section{Methodology}

\section{Participants}

Participants for the present study were recruited based on the sample from the Sri Lanka Diabetes and Cardiovascular 
Study (SLDCS), a national study conducted between 2005 and 2006. Detailed sampling procedures used in the SLDCS have been previously reported ${ }^{(2)}$. The current study was conducted between January and March 2011 during which time the researchers were able to collect data from the previously missing North and Eastern provinces in the SLDCS because of the improved security situation. In the original study, researchers randomly selected 100 clusters consisting of fifty individuals according to the probabilityproportional-to-size method, to gain a representative sample from seven of the nine provinces. From the 100 clusters, ten were randomly selected stratifying to the area of residence and ethnicity. To address the gap in national data from the remaining two provinces, we selected one cluster of fifty participants from the North and East by using 'Village Office Units' voter lists to randomly select one household. The remaining forty-nine households were selected applying the uniform method used in the SLDCS. In summary, the total sample in the present study comprised 600 individuals ( 500 from previous SLDCS areas and 100 additionally from the Northern and Eastern provinces). Those who were pregnant, lactating, acutely ill or on a therapeutic diet were excluded. The present study was approved by the Ethics Review Committee of the Faculty of Medicine, University of Colombo, Sri Lanka.

\section{Procedure}

The selected households were initially contacted via telephone by the study team who provided information regarding the study and verbal consent was taken. Where telephone facilities or contact telephone numbers were unavailable, households were visited by the study team with prior postal notice. Subsequently, households were visited on a random day to minimize bias for food selection. Dietary and demographic details were obtained after final written informed consent was obtained. An interviewer-administered questionnaire was used for data collection. Information regarding sociodemographic factors, timing of daily routines and meals was obtained.

\section{4 b dietary recall}

Two interviewers obtained dietary data by asking the participants what they ate in the previous $24 \mathrm{~h}$ in direct chronological order. To minimize the inter-personal variation, at the end of the day the two interviewers reviewed each other's work and maintained homogeneity of the recording procedure. Where there was a disparity in the dietary recalls, participants were re-contacted or the $24 \mathrm{~h}$ recall repeated on a different day. Food portion sizes were obtained using standard household measures such as plate, bowl, cup, glass and different spoons; these were clarified by demonstration using real utensils, a series of food portion size photographs and a food atlas $^{(5,6)}$. When participants recalled the amount of food consumed by weight, this value was entered.

\section{Data entry and analysis}

The daily food intake was divided into seven food groups: (i) cereal or equivalents (starchy foods); (ii) vegetables; (iii) fruits; (iv) meat or alternatives; (v) pulses; (vi) dairy; and (vii) added sugars. For the detailed methodology regarding the translation of food eaten into the respective food groups, see Supplementary Materials, Part 1.

\section{Metbod for translating food consumed into food group servings}

All food recorded in $24 \mathrm{~h}$ recall by each participant was assigned to one of the seven major food groups defined above. Food was recorded either in household measures (cups, spoons, etc.) or by weight in the $24 \mathrm{~h}$ recall and was translated into serving size for each food consumed. Thus, the weight of food in grams or the amount of household measure of food was divided by the weight of one serving or the amount of household measure for one serving and summed to derive servings of each food group. Food that was a mixture of several food types was disaggregated before ingredients were categorized into appropriate food groups. An example of disaggregation is illustrated in Fig. 1. A similar method was used for the US population for food grouping when food mixtures required disaggregation ${ }^{(7)}$. The servings of food consumed in mixed foods were calculated by modifying existing recipe files to develop a cascaded recipe file with multiple levels of breakdown. Common recipes were accepted after checking for face validity by consulting nutritionists; when in doubt, the respective households were contacted ${ }^{(8)}$. For uncommon food items, detailed recipes were collected at the time of the $24 \mathrm{~h}$ dietary recall from the participant or other responsible person in each household.

\section{Statistical analyses}

Average daily portion sizes were calculated as the total portion size divided by the number of participants. The sum of vegetable and fruit portions was divided to obtain average daily fruit and vegetable consumption, and the same method was used to calculate average daily meat and pulse intakes. We analysed the mean daily consumption of each food group according to gender using the two-sample $t$ test, to determine whether the mean values differed between genders. Data were analysed using the SPSS statistical software package version 14 (SPSS Inc.). In all analyses a $P$ value $<0 \cdot 05$ was considered statistically significant.

\section{Results}

Sample size was 490 (with a response rate of $82 \%$ ), of whom $34 \cdot 5 \%$ ( $n$ 169) were males. The sociodemographic profile of the study population is shown in Table 1 .

The estimated mean daily servings of the seven food groups from the random $24 \mathrm{~h}$ dietary recall, according to 


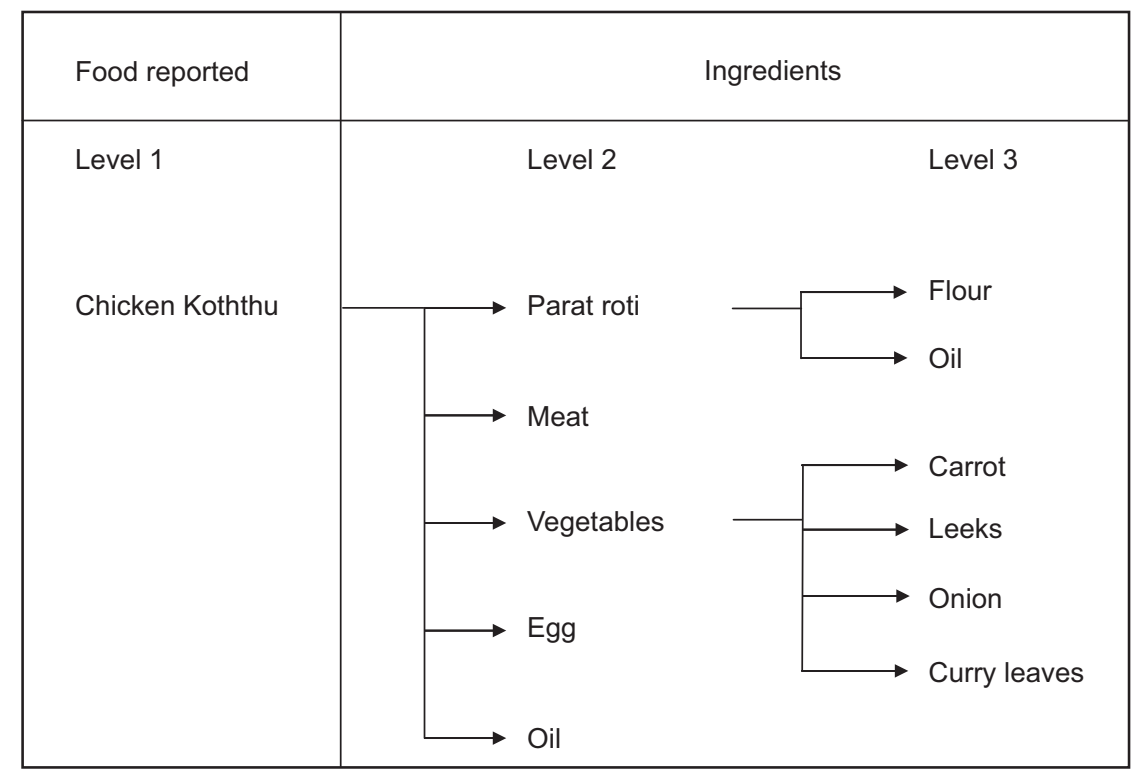

Fig. 1 Example of a disaggregated recipe showing multiple levels (Chicken Koththu)

Table 1 Demographic characteristics and BMI of the sample of Sri Lankan adults

\begin{tabular}{|c|c|c|c|c|}
\hline \multirow[b]{2}{*}{ Variable } & \multicolumn{2}{|c|}{ Males (n 169) } & \multicolumn{2}{|c|}{ Female ( $n$ 321) } \\
\hline & Mean or $\%$ & SD or $n$ & Mean or \% & SD or $n$ \\
\hline Age (years) & $48 \cdot 4$ & $15 \cdot 6$ & $48 \cdot 1$ & $14 \cdot 1$ \\
\hline \multicolumn{5}{|l|}{ Area of residence } \\
\hline Urban & $27 \cdot 8$ & 47 & $36 \cdot 1$ & 116 \\
\hline Rural & $60 \cdot 4$ & 102 & $57 \cdot 6$ & 185 \\
\hline Estate* & $11 \cdot 8$ & 20 & $6 \cdot 2$ & 20 \\
\hline \multicolumn{5}{|l|}{ Ethnicity } \\
\hline Sinhalese & $71 \cdot 0$ & 120 & $80 \cdot 1$ & 257 \\
\hline Muslim & $4 \cdot 7$ & 8 & $7 \cdot 2$ & 23 \\
\hline Sri Lankan Tamil & $11 \cdot 8$ & 20 & $7 \cdot 2$ & 23 \\
\hline Indian Tamil & $12 \cdot 4$ & 21 & $5 \cdot 6$ & 18 \\
\hline \multicolumn{5}{|l|}{ Education level } \\
\hline No schooling & $6 \cdot 5$ & 11 & $6 \cdot 5$ & 21 \\
\hline Up to 5 years & $27 \cdot 2$ & 46 & $25 \cdot 2$ & 81 \\
\hline Up to 11 years & $34 \cdot 9$ & 59 & $40 \cdot 5$ & 130 \\
\hline Up to 13 years & $27 \cdot 2$ & 46 & $22 \cdot 7$ & 73 \\
\hline Graduate & $4 \cdot 1$ & 7 & $5 \cdot 0$ & 16 \\
\hline BMI $\left(\mathrm{kg} / \mathrm{m}^{2}\right)$ & $21 \cdot 97$ & $3 \cdot 45$ & $23 \cdot 73$ & $4 \cdot 29$ \\
\hline
\end{tabular}

Data are presented as mean and standard deviation for age and $\mathrm{BMI}$; otherwise as percentage and frequency.

*Tea and rubber plantation zones.

gender, are shown in Table 2. In addition, the combined categories of fruits and vegetables and meat and pulses are also reported. Mean daily intake of fruit $(0.43)$ and vegetable $(1 \cdot 73)$ portions was well below minimum recommendations (fruits $>2$ portions/d; vegetables $>3$ portions/d). The total fruit and vegetable intake was $2 \cdot 16$ portions/d. Daily consumption of meat or alternatives was 1.75 portions and the sum of meat and pulses was $2 \cdot 78$ portions/d. On average, Sri Lankan adults consumed over 14 portions of starch/d; moreover, males consumed 5 more portions of cereal than females. Sri Lankan adults consumed on average 3.56 portions of added sugars/d.
Table 2 Average dietary intake of different food groups (portions/d) among the sample of Sri Lankan adults

\begin{tabular}{|c|c|c|c|c|c|c|}
\hline \multirow[b]{2}{*}{ Food group } & \multicolumn{2}{|c|}{ All adults } & \multicolumn{2}{|c|}{ Males } & \multicolumn{2}{|c|}{ Females } \\
\hline & Mean & SD & Mean & SD & Mean & SD \\
\hline arch & $14 \cdot 06$ & $5 \cdot 59$ & $\cdot 17$ & $6 \cdot 17$ & $12 \cdot 39$ & $4 \cdot 45$ \\
\hline Fru & $0 \cdot 43$ & $0 \cdot 62$ & $0 \cdot 44$ & $0 \cdot 77$ & 0.43 & 0.65 \\
\hline Vegetables & $1 \cdot 73$ & $1 \cdot 25$ & 1.95 & $1 \cdot 42$ & $1 \cdot 61$ & $1 \cdot 13$ \\
\hline Meat or alternatives & $1 \cdot 75$ & $1 \cdot 63$ & $1 \cdot 92$ & $1 \cdot 88$ & $1 \cdot 65$ & $1 \cdot 48$ \\
\hline Pulses & $1 \cdot 04$ & 1.01 & $1 \cdot 29$ & $1 \cdot 24$ & 0.90 & 0.83 \\
\hline Dairy & 0.39 & 0.46 & $0 \cdot 40$ & 0.48 & $0 \cdot 39$ & 0.45 \\
\hline$d d$ & 3.56 & $3 \cdot 10$ & $3 \cdot 64$ & $3 \cdot 34$ & $3 \cdot 51$ & $2 \cdot 97$ \\
\hline Frui & $2 \cdot 16$ & $1 \cdot 46$ & $2 \cdot 39$ & $1 \cdot 65$ & $2 \cdot 04$ & $1 \cdot 34$ \\
\hline Meat and pulses & $2 \cdot 78$ & $1 \cdot 87$ & $3 \cdot 22$ & $2 \cdot 14$ & $2 \cdot 55$ & $1 \cdot 66$ \\
\hline
\end{tabular}

Table 3 compares the food consumption of Sri Lankan adults with national ${ }^{(9)}$ and international (US) recommendations ${ }^{(10)}$.

We identified considerable variations in consumption frequency for each food type and their portion size in the study population. Table 4 illustrates the distribution of participants according to the number of portions of the main food groups, and their combinations, consumed. Starchy foods were consumed by everybody; over $88 \%$ met the minimum daily recommendations. Importantly, nearly $70 \%$ of adults exceeded the maximum daily recommendation for starch (11 portions/d) and a considerable proportion consumed larger numbers of starch servings daily, particularly men. More than $12 \%$ of men consumed $\geq 25$ starch servings/d. In contrast to their starch consumption, participants reported very low intakes of other food groups (Table 4). Only $11 \cdot 6 \%, 2 \cdot 1 \%$ and $3.5 \%$ of adults consumed the minimum daily recommended servings of vegetables, fruits and fruits and vegetables combined, respectively. Six out of ten adult 
Table 3 Comparison of the average food intake of Sri Lankan adults with national and international recommendations

\begin{tabular}{lccc}
\hline Food group & $\begin{array}{c}\text { Average intake of Sri Lankan } \\
\text { adults (portions/d) }\end{array}$ & $\begin{array}{c}\text { National recommendations } \\
\text { (portions/d) }\end{array}$ & $\begin{array}{c}\text { US recommendations }^{(10)} \\
\text { (portions/d) }\end{array}$ \\
\hline Starch & $14 \cdot 1$ & $6-11$ & $6-11$ \\
Fruits & $0 \cdot 4$ & $2-3$ & $2-4$ \\
Vegetables & $1 \cdot 7$ & $3-4$ & $3-5$ \\
Fruits and vegetables & $2 \cdot 1$ & $\geq 5$ & $\geq 5$ \\
Meat and pulses & $2 \cdot 8$ & $1-2$ & $2-3$ \\
Dairy & $0 \cdot 4$ & $1-2$ & $2-3$ \\
Added sugars & $3 \cdot 6$ & Low & Sparingly \\
\hline
\end{tabular}

Table 4 Percentage distribution of the sample of Sri Lankan adults according to their consumption of food portions from different food groups

\begin{tabular}{|c|c|c|c|c|}
\hline Food group & $\begin{array}{c}\text { No. of } \\
\text { portions/d }\end{array}$ & $\begin{array}{c}\text { All } \\
\text { adults }\end{array}$ & Males & Females \\
\hline \multirow[t]{4}{*}{ Vegetables } & $>0$ & $93 \cdot 2$ & $92 \cdot 3$ & $93 \cdot 6$ \\
\hline & $\geq 1$ & $74 \cdot 7$ & $70 \cdot 4$ & $63 \cdot 4$ \\
\hline & $\geq 2$ & 33.1 & $39 \cdot 1$ & $29 \cdot 9$ \\
\hline & $\geq 3$ & $11 \cdot 6$ & $16 \cdot 6$ & $8 \cdot 9$ \\
\hline \multirow[t]{3}{*}{ Fruits } & $>0$ & $39 \cdot 8$ & $36 \cdot 7$ & $41 \cdot 4$ \\
\hline & $\geq 1$ & $12 \cdot 4$ & $12 \cdot 4$ & $12 \cdot 4$ \\
\hline & $\geq 2$ & $2 \cdot 1$ & $2 \cdot 4$ & $1 \cdot 9$ \\
\hline \multirow[t]{6}{*}{ Fruits and vegetables } & $>0$ & 95.0 & 93.5 & 95.9 \\
\hline & $\geq 1$ & $74 \cdot 1$ & 76.9 & $72 \cdot 6$ \\
\hline & $\geq 2$ & $47 \cdot 4$ & $53 \cdot 8$ & $43 \cdot 9$ \\
\hline & $\geq 3$ & $23 \cdot 4$ & $26 \cdot 6$ & $21 \cdot 7$ \\
\hline & $\geq 4$ & 8.5 & 13 & $6 \cdot 1$ \\
\hline & $\geq 5$ & 3.5 & $5 \cdot 3$ & $2 \cdot 5$ \\
\hline \multirow[t]{6}{*}{ Starch } & $>0$ & $100 \cdot 0$ & $100 \cdot 0$ & $100 \cdot 0$ \\
\hline & $\geq 8$ & $88 \cdot 2$ & $95 \cdot 3$ & $84 \cdot 4$ \\
\hline & $\geq 11$ & 68.9 & $84 \cdot 6$ & $60 \cdot 5$ \\
\hline & $\geq 14$ & $41 \cdot 6$ & 63.9 & $29 \cdot 6$ \\
\hline & $\geq 20$ & $13 \cdot 7$ & $27 \cdot 2$ & $6 \cdot 4$ \\
\hline & $\geq 25$ & $5 \cdot 0$ & $12 \cdot 4$ & $1 \cdot 0$ \\
\hline \multirow[t]{4}{*}{ Pulses } & $>0$ & 74.9 & $75 \cdot 1$ & $74 \cdot 8$ \\
\hline & $\geq 1$ & 37.5 & $43 \cdot 2$ & $34 \cdot 4$ \\
\hline & $\geq 2$ & $12 \cdot 4$ & $21 \cdot 9$ & $7 \cdot 3$ \\
\hline & $\geq 3$ & $4 \cdot 6$ & 8.9 & $2 \cdot 2$ \\
\hline \multirow[t]{4}{*}{ Meat } & $>0$ & $78 \cdot 7$ & $72 \cdot 2$ & $82 \cdot 2$ \\
\hline & $\geq 1$ & $57 \cdot 6$ & $57 \cdot 4$ & $57 \cdot 6$ \\
\hline & $\geq 2$ & $32 \cdot 5$ & $36 \cdot 7$ & $30 \cdot 3$ \\
\hline & $\geq 3$ & $17 \cdot 8$ & $20 \cdot 7$ & $16 \cdot 2$ \\
\hline \multirow[t]{6}{*}{ Meat and pulses } & $>0$ & 95.9 & 95.9 & 95.9 \\
\hline & $\geq 1$ & 83.0 & $85 \cdot 2$ & $81 \cdot 8$ \\
\hline & $\geq 2$ & $59 \cdot 0$ & $65 \cdot 1$ & $55 \cdot 8$ \\
\hline & $\geq 3$ & $36 \cdot 2$ & $42 \cdot 6$ & $32 \cdot 8$ \\
\hline & $\geq 4$ & $19 \cdot 7$ & $30 \cdot 8$ & $17 \cdot 3$ \\
\hline & $\geq 5$ & $11 \cdot 6$ & $18 \cdot 9$ & $7 \cdot 6$ \\
\hline \multirow[t]{4}{*}{ Dairy } & $\geq 0$ & $61 \cdot 9$ & $60 \cdot 9$ & $62 \cdot 4$ \\
\hline & $\geq 0.5$ & $30 \cdot 0$ & $30 \cdot 8$ & $29 \cdot 6$ \\
\hline & $\geq 1$ & $5 \cdot 8$ & $4 \cdot 1$ & $6 \cdot 7$ \\
\hline & $\geq 2$ & 0.8 & $1 \cdot 2$ & 0.6 \\
\hline
\end{tabular}

Sri Lankans sampled did not consume any fruits. Milk and dairy consumption was extremely low; over a third of the population did not consume any dairy products and less than $1 \%$ of adults consumed 2 portions of dairy/d. A quarter of Sri Lankans did not report consumption of meat and pulses. Regarding protein consumption, 36.2\% attained the minimum Sri Lankan recommendation for protein; and significantly more men than women achieved the recommendation of $\geq 3$ servings of meat or alternatives daily (men $42 \cdot 6 \%$, women $32 \cdot 8 \% ; P<0 \cdot 05$ ).

\section{Discussion}

Recently, the WHO STEP Survey reported on some dietary aspects from one health area in the Western Province ${ }^{(11)}$ but, apart from this, the present study represents the first national-level dietary survey undertaken in Sri Lanka to obtain habitual dietary intake data of the general population. As the UK National Nutrition and Dietary Survey (NDNS) collected dietary details from 1724 participants from a population of 60 million, we believe that the sample size of 600 used in the current study is within adequate limits.

During the last 5 years, Sri Lanka has faced significant urbanization and this has resulted in some previous study clusters changing from rural to urban status. While the present study population is reasonably representative of all major ethnic groups in the country, there were higher proportions of urban living, aged and participants with a higher BMI compared with previous surveys ${ }^{(12)}$. Our results showed a low mean daily intake of fruits and vegetables among Sri Lankan adults ( $2 \cdot 16$ portions) compared with the USA $(3 \cdot 0)$ and France $(3 \cdot 6)^{(13)}$. The low intake of fruits and vegetables may be a contributing factor to the high prevalence of diet-associated NCD such as diabetes, non-alcoholic fatty liver disease and CVD in Sri Lanka compared with other countries ${ }^{(3)}$. The specific reason for the low intake of fruits and vegetables is unclear; studies from developed countries suggest a lack of perceived social pressure to increase fruit and vegetable intake and that increased public health efforts require stronger health messages that incorporate consumer awareness of the low consumption levels ${ }^{(14)}$. Moreover, people's low purchasing ability and seasonal variation of fruit and vegetable prices may adversely affect consumption. Despite five servings of fruits and vegetables being considered the minimum daily intake by national dietary guidelines ${ }^{(9)}$, nearly half of the population eats less than two portions of fruits and vegetables daily, with less than $4 \%$ reaching the minimum recommendation. Somatunga reported that $96.9 \%$ of Sri Lankan adults did not consume five fruits and vegetables daily in the WHO STEP Survey (2004) undertaken in the Western Province of Sri Lanka, comparable to our findings ${ }^{(11)}$.

Pulses were the main source of protein, mainly as $\mathrm{dhal}$, the most common curry in the local context, and boiled 
pulses eaten for breakfast. Although pulses are grouped in the protein category, the main nutrient is carbohydrate, and thus invariably consumption of pulses masks significant amounts of carbohydrate. There is no conclusive evidence regarding protein intake and disease risk in Sri Lanka. The MASALA (Metabolic Syndrome and Atherosclerosis in South Asians Living in America) Study reported that higher levels of protein consumption are associated with increased odds of diabetes in South Asians independent of age, sex, waist circumference and hypertension ${ }^{(15)}$. A significant proportion of Sri Lankan males (data not shown) consumed over 5 servings of meat/d.

Sri Lankans consumed large numbers of starch servings; nearly $65 \%$ consumed well above the upper cutoff of the recommendations (food pyramid guidelines) and a considerable proportion of males consumed very high levels of starch. This is mainly due to the average person's meal comprising three-quarters rice with a small amount of vegetable curry (averaging $15 \mathrm{~g}$ ), a small piece of meat or fish $(15 \mathrm{~g})$ and some starchy curry such as potato or dhal (see Supplementary Materials, Part 2). Relatively low levels of starch portions were consumed by females mainly due to low absolute food intake. A high-carbohydrate meal leads to negative metabolic consequences such as hyperinsulinaemia, high serum TAG and low HDL-cholesterol levels ${ }^{(16)}$. Most Sri Lankans consume the largest starch portion for lunch or dinner and limit themselves to three meals per day (data not shown), which may cause postprandial hyperglycaemia and hypertriacylglycerolaemia ${ }^{(16)}$. More than a fifth of Sri Lankan adults are dysglycaemic and the prevalence of diabetes is alarmingly high ${ }^{(2)}$; the high consumption of carbohydrate may be associated with the diabetes epidemic in the country.

Dairy products provide valuable nutrients such as $\mathrm{Ca}$, which is important for building and maintaining strong bones. In addition, milk products provide several essential nutrients such as proteins, vitamins and minerals. Lekamwasam and colleagues reported a $45 \%$ prevalence of osteoporosis among postmenopausal women in Sri Lanka ${ }^{(17)}$. The CARDIA (Coronary Artery Risk Development in Young Adults) Study revealed that dairy consumption was inversely associated with the incidence of all individual components of insulin resistance syndrome among individuals with a BMI $\geq 25 \mathrm{~kg} / \mathrm{m}^{2}$ and increased dairy consumption may reduce risk of type 2 diabetes and $\mathrm{CVD}^{(18)}$. Dairy intake in the present sample was substantially lower than Sri Lankan recommendations; over a third of the population did not consume any dairy products and only $5 \%$ reached minimum levels. The main reason behind the low dairy consumption could be that dairy products are unaffordable; their price is high mainly due to the lack of local production and their consumption depends largely on imported milk powder ${ }^{(19)}$.

This first national-level dietary survey provides a sound basis for future food policy as it affects Sri Lankan adults and for the development of relevant nutrition education programmes. Furthermore, the rational assessment of food portion exchange tables will offer health professionals, such as nutritionists, general practitioners and nurses, valuable insights into Sri Lankan meals and aid the development and prescription of meal plans in clinical and community settings. A major strength of our study was the recruitment of a representative group from all ethnic, education, areas of residence and age groups. Despite the relatively low participation of male participants, women's diet composition is similar to that of their male counterparts as most Sri Lankan men eat at home. Second, the use of a random $24 \mathrm{~h}$ dietary recall method helped to obtain accurate results regarding dietary habits. While a single day's food record cannot be used to generalize an individual's usual diet, $24 \mathrm{~h}$ recall data can provide estimates of group means. Third, disaggregation of food in Sri Lankan dishes into guideline-based food groups leads to the more accurate counting of small portions of foods in respective groups (as shown in Fig. 1). The main limitation of our data collection and analysis was the lack of data on oil consumption. Unlike meals in Western countries, coconut oil, coconut milk or scraped coconuts are included in most mixed dishes, which leads to significant methodological challenges in obtaining accurate measurements of fat intake ${ }^{(20)}$. Second, portion sizes were estimated by recalling commonly used utensils and demonstrating standard spoons, cups and plates, in addition to series of food photographs.

\section{Conclusions}

Dietary guidelines have emphasized the importance of a balanced and varied diet. Meals that include no servings or very few servings of different food groups such as fruits and vegetables, dairy products, fish and meat and pulses, lack both balance and variety. It is evident that a substantial proportion of the Sri Lankan population does not consume a varied and balanced diet, which is suggestive of a close association between the nutrition-related NCD in the country and these unhealthy eating habits. We recommend that government, health institutions and organizations conduct larger national-level dietary and nutrition surveys periodically to identify associated disease conditions. This would allow practical public health initiatives to improve the quality of the Sri Lankan diet.

\section{Acknowledgements}

This research received no specific grant from any funding agency in the public, commercial or not-for-profit sectors. The authors declare that they have no conflicts of interest. R.J. contributed to the data collection, data analysis and drafted the manuscript. N.M.B., M.J.S., P.K. and A.P.H. were the supervisory team on the project and contributed 
to the study design, data interpretation and revision of the manuscript. All authors read and approved the final manuscript. The authors would like to acknowledge Miss Fathima Shakira and other members in the Diabetes Research Unit, Colombo, for their contribution in arranging logistics for the study. The authors also thank Dr Senarath Mahamithawa (Deputy Director - Nutrition, Ministry of Health, Sri Lanka), Mrs Thakshila Adikari (Head, Department of Applied Nutrition, Wayamba University of Sri Lanka) and Miss Jyh Eiin Wong (Public Health Nutritionist, Department of Human Nutrition, University of Otago) for their input on data interpretation and expert comments.

\section{Supplementary Materials}

For Supplementary Materials for this article, please visit http://dx.doi.org/10.1017/S1368980012003011

\section{References}

1. Wijewardene K, Mohideen MR, Mendis S et al. (2005) Prevalence of hypertension, diabetes and obesity: baseline findings of a population based survey in four provinces in Sri Lanka. Ceylon Med J 50, 62-70.

2. Katulanda P, Constantine GR, Mahesh JG et al. (2008) Prevalence and projections of diabetes and pre-diabetes in adults in Sri Lanka - Sri Lanka Diabetes, Cardiovascular Study (SLDCS). Diabet Med 25, 1062-1069.

3. Abeywardena M (2003) Dietary fats, carbohydrates and vascular disease: Sri Lankan perspectives. Atherosclerosis 171, 157-161.

4. Krebs-Smith S, Cleveland LE, Ballard-Barbash $\mathrm{R}$ et al. (1997) Characterizing food intake patterns of American adults. Am J Clin Nutr 65, 4 Suppl., 1264S-1268S.

5. Nelson M, Atkinson M \& Meyer J (1997) A Photographic Atlas of Food Portion Sizes. London: MAFF Publications.

6. Suzana S, Noor Aini MY, Nik Shanita S et al. (2009) Atlas of Food Exchanges \& Portion Sizes. Kuala Lampur: MDC Publishers.
7. Cleveland L, Cook DA, Krebs-Smith SM et al. (1997) Method for assessing food intakes in terms of servings based on food guidance. Am J Clin Nutr 65, 4 Suppl., 1254S-1263S.

8. Dissanayake C (2010) Ceylon Cookery, 9th ed. Sri Lanka: Stamford Lake (Pvt) Ltd.

9. Nutrition Division, Ministry of Health (2011) Food Based Dietary Guidelines for Sri Lanka, 2nd ed. Colombo: Nutrition Division, Ministry of Health; available at http://203.94. 76.60/departmnt/NutritionDivision/Nutrition\%20Guidelines/ FBDG-English.pdf

10. US Department of Agriculture (1992) The Food Guide Pyramid. Home and Garden Bulletin no. 252. Washington, DC: USDA Center for Nutrition Policy and Promotion.

11. Somatunga LC (2004) NCD Risk Factor Survey in Sri Lanka (STEP Survey). Geneva: WHO.

12. Katulanda P, Jayawardena MA, Sheriff MH et al. (2010) Prevalence of overweight and obesity in Sri Lankan adults. Obes Rev 11, 751-756.

13. Tamers SL, Agurs-Collins T, Dodd KW et al. (2009) US and France adult fruit and vegetable consumption patterns: an international comparison. Eur J Clin Nutr 63, 11-17.

14. Levin A (1999) Nutrition and policy. 5: Who should teach patients about nutrition? Ann Intern Med 131, 317-318.

15. Wang ET, de Koning L \& Kanaya AM (2010) Higher protein intake is associated with diabetes risk in South Asian Indians: The Metabolic Syndrome and Atherosclerosis in South Asians Living in America (MASALA) Study. J Am Coll Nutr 29, 130-135.

16. Misra A, Khurana L, Isharwal S et al. (2009) South Asian diets and insulin resistance. Br J Nutr 101, 465-473.

17. Lekamwasam S, Wijayaratne L, Rodrigo M et al. (2007) Prevalence of osteoporosis among postmenopausal women in Sri Lanka: a cross-sectional community study. APLAR J Rheumatol 10, 234-238.

18. Pereira MA, Jacobs DR Jr, Van Horn L et al. (2002) Dairy consumption, obesity, and the insulin resistance syndrome in young adults the CARDIA study. JAMA 287, 2081-2089.

19. Food and Agriculture Organization of the United Nations (2007) Sri Lanka - Dairy Products. FAO Briefs on Import Surges - Countries no. 8. Rome: Trade and Markets Division (EST), FAO.

20. Amarasiri WA \& Dissanayake AS (2006) Coconut fats. Ceylon Med J 51, 47-51. 